American Journal of Applied Sciences 9 (4): 478-483, 2012

ISSN 1546-9239

(C) 2012 Science Publications

\title{
Machining Performance Study on Metal Matrix Composites-A Response Surface Methodology Approach
}

\author{
${ }^{1}$ Srinivasan, A., \\ ${ }^{1}$ R.M. Arunachalam, ${ }^{1}$ S. Ramesh and ${ }^{2}$ J.S. Senthilkumaar \\ ${ }^{1}$ Department of Mechanical Engineering, \\ Sona College of Technology, Salem, Tamil Nadu, India \\ ${ }^{2}$ Department of Mechanical Engineering, \\ Varuvan Vadivelan Institute of Technology, Dharmapuri, Tamil Nadu, India
}

\begin{abstract}
Problem statement: Metal Matrix Composites (MMC) have become a leading material among composite materials and in particular, particle reinforced aluminum MMCs have received considerable attention due to their excellent engineering properties. These materials are known as the difficult-to-machine materials because of the hardness and abrasive nature of reinforcement elementlike Alumina $\left(\mathrm{Al}_{2} \mathrm{O}_{3}\right)$. Approach: In this study, an attempt has been made to model the machinability evaluation through the response surface methodology in machining of homogenized $10 \%$ micron $\mathrm{Al}_{2} \mathrm{O}_{3}$ LM25 Al MMC manufactured through stir casting method. Results: The combined effects of three machining parameters including cutting speed (s), feed rate (f) and depth of cut (d) on the basis of three performance characteristics of tool wear (VB), surface Roughness (Ra) and cutting Force (Fz) were investigated. The contour plots were generated to study the effect of process parameters as well as their interactions. Conclusion: The process parameters are optimized using desirability-based approach response surface methodology.
\end{abstract}

Key words: Metal Matrix Composites (MMC), Optimization, Response Surface Methodology (RSM), Tool wear, Surface roughness, Cutting force

\section{INTRODUCTION}

Metal Matrix Composites (MMC) is widely used composite materials in aerospace, automotive, electronics and medical industries. They have outstanding properties like high strength, low weight, high modules, low ductility, high wear resistance, high thermal conductivity and low thermal expansion. These desired properties are mainly manipulated by the matrix, the reinforcement element and the interface. Some of the typical applications are bearings, automobile pistons, cylinder liners, piston rings, connecting rods, sliding electrical contacts, turbo charger impellers, space structures. The most popular reinforcements are Silicon Carbide ( $\mathrm{SiC}$ ) and Alumina $\left(\mathrm{Al}_{2} \mathrm{O}_{3}\right)$. Aluminum, titanium and magnesium alloys are commonly used as the matrix phase. The density of most of the MMCs is approximately one third that of steel, resulting in high-specific strength and stiffness.

Hashim et al. (1999) have identified four technical difficulties in stir casting: difficulty of achieving a uniform distribution of the reinforcement material; wettability between the two main substances; porosity in the cast metal matrix composites; and chemical reactions between the reinforcement material and the matrix alloy. These difficulties need to be overcome in order achieve a MMC with a broad range of mechanical properties. They have also identified the important process variables that affect the mechanical properties of MMC. The holding temperature, stirring speed, size of the impeller and the position of the impeller in the melt are to be considered in the production of cast metal matrix composites.

Sahin (2003) has developed a setup for manufacturing MMCs. The setup has a bottom tapping facility. He has evaluated three methods for mixing of the reinforcement and has achieved full and homogenous distribution of the particles in the matrix alloy. However, the setup does not have the facility to change the positioan of the impeller in the melt. If investigated, this could further enhance the quality of the MMCs produced. The pouring molten mixture is tapped from the bottom of the crucible after mixing process is completed. Hardness of the aluminium alloy improved significantly by addition of $\mathrm{SiC}$ particles into it, while density of the composite also increased almost linearly with the weight fraction of particles. 
Am. J. Applied Sci., 9 (4): 478-483, 2012

The main problem, in case of $10 \mathrm{wt} \%$ of micron alumina reinforced with LM25 aluminium alloy machining, is that it is known as the difficult-tomachine material, because of the existence of hard abrasive reinforcement particles are harder. This material extremely difficult to machine and lead to increase the machining time, cost of machining and consequently high wear rate of cutting tools during machining. These three main parameters influence the machinability and costs of machining are cutting force, tool life and surface finish. These response parameters are having functional relationship with the independent machining parameters of cutting speed, feed and depth of cut. Machining is the very old process; hence very little changes have taken place throughout the several decades of time period. But in recent years, machining parameter optimization inevitable to the process planner in order to ensure the product quality and reduce the machining cost has come to vogue. However high speed machining significantly improves the productivity, but it cannot be employed in all machines and processes. In machining of parts, surface quality is one of most specified technical requirements in order to achieve compact assembly of machined components. The major indication of surface quality on machined part is surface finish which directly relies on tool geometry and machining parameters. Tool geometry like nose radius, edge geometry, rake angle can be controlled by the tool manufacturer whereas machining parameters are have to be optimized. In finish turning, tool wear becomes an additional parameter affecting surface quality of finished parts.

Several studies have been done in order to examine the efficiency of different cutting tool materials, such as cemented carbide, coated carbide and diamond in turning, milling, drilling, reaming and threading of MMC materials. The main problem while machining MMC is the extensive tool wear caused by the very hard and abrasive reinforcements. Mannaa and Bhattacharya (2003) investigated the machinability of $\mathrm{Al} / \mathrm{SiC} \mathrm{MMC}$ and found that no Built-Up Edge (BUE) is formed during machining of $\mathrm{Al} / \mathrm{SiC} \mathrm{MMC}$ at high speed and low depth of cut and also observed a better surface finish at high speed with low feed rate and low depth of cut.

Davim (2007) compared the performance of brazed Polycrystalline Diamond (PCD) with CVD diamond coated tools during machining of MMCs. The results indicated that PCD insert tools have longer tool life and better surface roughness and also found CVD diamond coated tools show short life, as tool wear evolution becomes very fast after coating rupture (Davim, 2002). Pramanik et al. (2006) developed a mechanics model for predicting the forces when machining aluminum alloy based MMCs reinforced with ceramic particles.
The predictions revealed that the force due to chip formation is much higher than those due to plowing and particle fracture.

Kilıckap et al. (2005) examined homogenised 5\% SiC-p aluminium MMC material was selected for experimental investigation of tool wear and surface roughness. Two types of K10 cutting tool (uncoated and $\mathrm{TiN}$-coated) were used at different cutting speeds $\left(50,100\right.$ and $\left.150 \mathrm{~m} \mathrm{~min}^{-1}\right)$, feed rates $(0.1,0.2$ and 0.3 $\mathrm{mm} / \mathrm{rev})$ and depths of cut $(0.5,1$ and $1.5 \mathrm{~mm})$. In dry turning condition, tool wear was mainly affected by cutting speed, increased with increasing cutting speed. Tool wear was lower when coated cutting tool was used in comparison to uncoated one. SiC-p aluminium MMC material was selected for experimental investigation of tool wear and surface roughness. Two types of K10 cutting tool (uncoated and TiN-coated) were used at different cutting speeds $(50,100$ and $150 \mathrm{~m} / \mathrm{min})$, feed rates $(0.1,0.2$ and $0.3 \mathrm{~mm} / \mathrm{rev})$ and depths of cut $(0.5,1$ and $1.5 \mathrm{~mm})$. In dry turning condition, tool wear was mainly affected by cutting speed, increased with increasing cutting speed. Tool wear was lower when coated cutting tool was used in comparison to uncoated one.

From the literature it is found that the machining of $\mathrm{Al}-\mathrm{MMC}$ is an important area of research, but only very few studies have been carried out on optimization of tool wear (VBmax), surface Roughness (Ra) and cutting Force $(\mathrm{Fz})$ while machining of Particulate Aluminum Metal Matrix Composite (PAMMC). Hence, the main objective of the present study is to optimize tool wear, surface roughness and cutting force while machining LM25 Al-Al2O3 metal matrix composite using RSM.

\section{Design of experiment based on response surface methodology: Response Surface Methodology (RSM)} is the collection of experimental strategies, mathematical methods and statistical inferences that enable an experimenter to make efficient empirical exploration of the system of interest. RSM can be defined as a statistical method that uses quantitative data from appropriate experiments to determine and simultaneously solve multi-variable equations. The work which initially generated interest in the package of techniques was a paper by (Box and Wilson, 1951). Iqbal and Khan (2010) have been involved in developing prediction models using this renowned response surface methodology for their machining studies.

This method is now broadly used in many fields, such as chemistry, biology and manufacturing.

RSM can be used in the following ways: 
Am. J. Applied Sci., 9 (4): 478-483, 2012

- To determine the factor levels that will simultaneously satisfy a set of desired specifications

Table 1: Chemical compositions of aluminium alloy (LM25) \% Wt

\begin{tabular}{llllllll}
\hline $\mathrm{Cu}$ & $\mathrm{Si}$ & $\mathrm{Mg}$ & $\mathrm{Fe}$ & $\mathrm{Mn}$ & $\mathrm{Ni}$ & $\mathrm{Zn}$ & $\mathrm{Pb}$ \\
\hline 0.20 & 7.50 & 0.06 & 0.50 & 0.30 & 0.10 & 0.10 & 0.10
\end{tabular}

- To determine the optimum combination of factors that yields a desired response and describes the response near the optimum

- To determine how a specific response is affected by changes in the level of the factors over the specified levels of interest

- To achieve a quantitative understanding of the system behavior over the region tested

- To predict product properties throughout the region, even for a factor combinations not actually run

- To find the conditions necessary for process stability (insensitive spot)

In design optimization using RSM, the first task is to determine the optimization model, such as the identification of the interested system measures and the selection of the factors that influence the system measures significantly. To do this, an understanding of the physical meaning of the problem and some experience are both useful. After this, the important issues are the design of experiments and how to improve the fitting accuracy of the response surface models.

Experimental procedure: Single pass finish turning operation is conducted in dry cutting condition in order to investigate the performance and study the wear mechanism of uncoated cemented carbide tools on Metal matrix composites in the form of cylindrical bar stock of diameter $80 \mathrm{~mm}$. The experiments were conducted on Kirloskar Turnmaster all geared type lathe machine.

Work material: LM25 aluminium alloy metal matrix composite material is used as the work material in the present investigation. Test specimen was prepared from cylindrical bar of $270 \mathrm{~mm}$ long and $80 \mathrm{~mm}$ diameter. The chemical composition is given in Table 1 .

Tool material: Uncoated cemented carbide inserts as per ISO specification SNMG 120408-QM H13A cutting tool was supplied by Sandvick and tool holder CTANR 2525-M16 type were used for the turning trials under dry cutting condition.

Experimental set-up: The tests were conducted under different cutting conditions using an Kirloskar Turnmaster all geared type lathe machine, which is $3 \mathrm{HP} / 2.2 \mathrm{~kW}$ power. The cutting speed was derived from the measured spindle speed and the diameter of the surface of the work piece. The tests were carried out without coolant at a varying depth of cut and feed rate.

Table 2: Cutting parameters and their levels

\begin{tabular}{llrlr}
\hline Machining parameters & Unit & Level 1 & Level 2 & Level 3 \\
\hline Cutting speed (V) & $\mathrm{m} / \mathrm{min}$ & 100.0 & -- & 125.0 \\
Feed (f) & $\mathrm{mm} / \mathrm{rev}$ & 0.1 & 0.15 & 0.2 \\
Depth of cut (a) & $\mathrm{mm}$ & 0.5 & 0.75 & 1.0 \\
\hline
\end{tabular}

Table 3: Turning conditions and machining responses of MMCs

\begin{tabular}{|c|c|c|c|c|c|}
\hline \multicolumn{3}{|c|}{ Machining parameters } & \multicolumn{3}{|c|}{ Response variables } \\
\hline $\begin{array}{l}\text { Cutting } \\
\text { peed 'V' } \\
\text { (m/min) }\end{array}$ & $\begin{array}{l}\text { Feed 'f' } \\
(\mathrm{mm} / \mathrm{rev})\end{array}$ & $\begin{array}{l}\text { Depth } \\
\text { of cut } \\
\text { 'a' (mm) }\end{array}$ & $\begin{array}{l}\text { Tool } \\
\text { wear } \\
\left(\mathrm{V}_{\mathrm{B}}\right)\end{array}$ & $\begin{array}{l}\text { Surface } \\
\text { roughness } \\
\text { 'Ra' }(\mu \mathrm{m})\end{array}$ & $\begin{array}{l}\text { Cutting } \\
\text { Force } \\
\text { 'Fz' }(\mathrm{N})\end{array}$ \\
\hline 100 & 0.10 & 0.50 & 0.08 & 1.03 & 48.84 \\
\hline 100 & 0.10 & 0.75 & 0.07 & 0.80 & 29.22 \\
\hline 100 & 0.10 & 1.00 & 0.09 & 1.28 & 152.30 \\
\hline 100 & 0.15 & 0.50 & 0.06 & 1.42 & 87.29 \\
\hline 100 & 0.15 & 0.75 & 0.08 & 1.56 & 196.78 \\
\hline 100 & 0.15 & 1.00 & 0.08 & 1.66 & 306.20 \\
\hline 100 & 0.20 & 0.50 & 0.13 & 1.70 & 260.08 \\
\hline 100 & 0.20 & 0.75 & 0.90 & 1.17 & 238.76 \\
\hline 100 & 0.20 & 1.00 & 0.10 & 0.98 & 244.64 \\
\hline 125 & 0.10 & 0.50 & 0.09 & 1.01 & 44.36 \\
\hline 125 & 0.10 & 0.75 & 0.06 & 0.97 & 146.65 \\
\hline 125 & 0.10 & 1.00 & 0.09 & 1.53 & 149.08 \\
\hline 125 & 0.15 & 0.50 & 0.80 & 1.61 & 107.80 \\
\hline 125 & 0.15 & 0.75 & 0.90 & 1.81 & 117.73 \\
\hline 125 & 0.15 & 1.00 & 0.10 & 1.39 & 120.57 \\
\hline 125 & 0.20 & 0.50 & 0.13 & 2.36 & 101.20 \\
\hline 125 & 0.20 & 0.75 & 0.13 & 2.24 & 147.46 \\
\hline 125 & 0.20 & 1.00 & 0.08 & 1.57 & 179.74 \\
\hline
\end{tabular}

The levels were specified for each process parameter as given in the Table 2. The parameter levels were chosen within the intervals recommended by the cutting tool manufacturer and investigation of the present study. Three process parameters at two and three levels led to a total of 18 tests for turning operation. After each test, , the worn cutting tool is measured with the optical tool microscope to determine the degree of flank wear, the surface roughness measured by TR100 surface roughness tester and cutting force measured by kistler dynamometer (SN type). The observations are presented in the Table 3 for further analysis and studies. The machining operations were carried out as per the conditions given by the design matrix at random to avoid systematic errors.

\section{MATERIALS AND METHODS}

Mathematical modeling:

Models for uncoated cemented carbide tools: Table 4 shows the ANOVA table for RSM model for tool wear when machining MMC with uncoated tool.

The regression model fitted for tool wear was obtained and is represented by Eq. 1:

Tool wear $(\mathrm{VB})=0.088889-0.000556$

$\times \mathrm{V}-0.007500 \times f+0.025000 \times \mathrm{d}-0.015833$

$\times \mathrm{f}^{2}+0.036667 \mathrm{x} \mathrm{d} 2+0.022500 \times \mathrm{V}$

$\times f-0.010000 \times \mathrm{V} \times \mathrm{d}-0.001250 \times \mathrm{f} \times \mathrm{d}$ 
Am. J. Applied Sci., 9 (4): 478-483, 2012

Table 4: ANOVA table for response surface function of the tool wear

\begin{tabular}{lllllll}
\hline Source & DF & Seq SS & Adj SS & Adj MS & F & P \\
\hline Regression & 8 & 0.021849 & 0.021849 & 0.002731 & 2.43 & 0.104 \\
Linear & 3 & 0.008181 & 0.008181 & 0.002727 & 2.43 & 0.133 \\
Square & 2 & 0.006381 & 0.006381 & 0.003190 & 2.84 & 0.111 \\
Interaction & 3 & 0.007288 & 0.007288 & 0.002429 & 2.16 & 0.162 \\
Residual Error & 9 & 0.010112 & 0.010112 & 0.001124 & & \\
Total & 17 & 0.031961 & & & & \\
\hline
\end{tabular}

Table 5: ANOVA table for response surface function of the surface roughness

\begin{tabular}{lrlllll}
\hline Source & DF Seq SS & Adj SS & Adj MS & F & P \\
\hline Regression & 8 & 0.51700 & 0.516997 & 0.064625 & 1.18 & 0.402 \\
Linear & 3 & 0.29061 & 0.290614 & 0.096871 & 1.77 & 0.223 \\
Square & 2 & 0.09512 & 0.095125 & 0.047562 & 0.87 & 0.452 \\
Interaction & 3 & 0.13126 & 0.131258 & 0.043753 & 0.80 & 0.525 \\
Residual Error & 9 & 0.49265 & 0.492653 & 0.054739 & & \\
Total & 17 & 1.00965 & & & & \\
\hline
\end{tabular}

Table 6: ANOVA table for response surface function of the cutting force

\begin{tabular}{lcrrrrr}
\hline Source & DF & Seq SS & Adj SS & Adj MS & \multicolumn{1}{c}{ F } & P \\
\hline Regression & 8 & 83415.5 & 83415.5 & 10426.9 & 8.11 & 0.003 \\
Linear & 3 & 68739.4 & 68739.4 & 22913.1 & 17.81 & 0.000 \\
Square & 2 & 4464.7 & 4464.7 & 2232.4 & 1.74 & 0.230 \\
Interaction & 3 & 10211.4 & 10211.4 & 3403.8 & 2.65 & 0.113 \\
Residual Error & 9 & 11576.4 & 11576.4 & 1286.3 & & \\
Total & 17 & 94991.8 & & & & \\
\hline
\end{tabular}

Table 7: Predicted result with experimental validation of micron MMCs for tool wear

\begin{tabular}{|c|c|c|c|c|c|c|}
\hline \multirow{2}{*}{$\begin{array}{l}\text { Prediction } \\
\text { method } \\
\text { Taguchi } \\
\text { Analysis }\end{array}$} & \multicolumn{3}{|c|}{ Machining parameters } & \multicolumn{3}{|c|}{ Tool wear ' $\mathrm{V}_{\mathrm{B}}$ ' $(\mathrm{mm})$} \\
\hline & $\begin{array}{l}\text { Cutting } \\
\text { speed 'v' } \\
(\mathrm{m} / \mathrm{min})\end{array}$ & $\begin{array}{l}\text { Feed 'f' } \\
(\mathrm{mm} / \mathrm{rev})\end{array}$ & $\begin{array}{l}\text { Depth } \\
\text { of cut } \\
\text { 'a' }(\mathrm{mm})\end{array}$ & $\begin{array}{l}\text { Predicted } \\
\text { ' } \mathrm{V}_{\mathrm{B}} \text { ' }\end{array}$ & $\begin{array}{l}\text { Actual } \\
\text { ' } \mathrm{V}_{\mathrm{B}} \text { ' }\end{array}$ & $\begin{array}{l}\text { Error } \\
(\%)\end{array}$ \\
\hline $\begin{array}{l}\text { Optimization } \\
\text { for tool wear }\end{array}$ & 100 & 0.15 & 1.00 & 0.17 & 0.15 & 11 \\
\hline
\end{tabular}

Table 8:Predicted result with experimental validation of micron MMCs for Surface

\begin{tabular}{|c|c|c|c|c|c|c|}
\hline \multirow[b]{2}{*}{$\begin{array}{l}\text { Prediction } \\
\text { method } \\
\text { Taguchi Analysis }\end{array}$} & \multicolumn{3}{|c|}{ Machining parameters } & \multicolumn{3}{|c|}{ Surface roughness 'Ra' $(\mu \mathrm{m})$} \\
\hline & $\begin{array}{l}\text { Cutting } \\
\text { speed 'v' } \\
(\mathrm{m} / \mathrm{min})\end{array}$ & $\begin{array}{l}\text { Feed 'f' } \\
\text { (mm/rev) }\end{array}$ & $\begin{array}{l}\text { Depth } \\
\text { of cut 'a' } \\
\text { (mm) }\end{array}$ & $\begin{array}{l}\text { Predicted } \\
\text { 'Ra' }\end{array}$ & $\begin{array}{l}\text { Actual } \\
\text { 'Ra' }\end{array}$ & $\begin{array}{l}\text { Error } \\
(\%)\end{array}$ \\
\hline $\begin{array}{l}\text { Optimization for } \\
\text { surface roughness }\end{array}$ & 100 & 0.15 & 1.00 & 1.51 & 1.40 & 7.2 \\
\hline
\end{tabular}

Table 9:Predicted result with experimental validation of micron MMCs for cutting force

\begin{tabular}{|c|c|c|c|c|c|c|}
\hline \multirow[b]{2}{*}{$\begin{array}{l}\text { Prediction method } \\
\text { Taguchi Analysis }\end{array}$} & \multicolumn{3}{|c|}{ Machining parameters } & \multicolumn{3}{|c|}{ Cutting Force ' $\mathrm{F}_{\mathrm{Z}}$ '(N) } \\
\hline & $\begin{array}{l}\text { Cutting } \\
\text { speed 'v' } \\
(\mathrm{m} / \mathrm{min})\end{array}$ & $\begin{array}{l}\text { Depth } \\
\text { Feed 'f' } \\
(\mathrm{mm} / \mathrm{rev})\end{array}$ & $\begin{array}{l}\text { of cut 'a' } \\
(\mathrm{mm})\end{array}$ & $\begin{array}{l}\text { Predicted } \\
\text { ' } \mathrm{F}_{\mathrm{Z}} \text { ' }\end{array}$ & $\begin{array}{l}\text { Actual } \\
\text { ' } \mathrm{F}_{\mathrm{Z}} \text { ' }\end{array}$ & $\begin{array}{l}\text { Error } \\
(\%)\end{array}$ \\
\hline $\begin{array}{l}\text { Optimization for } \\
\text { Cutting Force }\end{array}$ & 100 & 0.15 & 1.00 & 182.4 & 175.25 & 3.9 \\
\hline
\end{tabular}

The value of " $\mathrm{P}$ " in Table 4 for model is less than 0.05 which indicates that the model is adequately significant at $95 \%$ confidence level, which is desirable as it indicates that the terms in the model have a significant effect on the response. The cutting speed has the most dominant effect on tool wear, followed by the feed and the depth of cut. This is expected because, it is well known that increase in cutting speed will increase tool wear, the classical wear rate is primarily a function of the cutting speed (Shaw, 2005). Similarly the following tables and equations are obtained for different responses.

Table 5 shows the ANOVA table for RSM model for surface roughness when machining MMC with uncoated tool.

The regression model fitted for surface roughness was obtained and is represented by Eq. 2:

Surface roughness $(\mathrm{Ra})=1.21333-0.05056 \times \mathrm{V}+$

$0.12250 \times \mathrm{f}+0.07333 \times \mathrm{d}+0.05250 \times \mathrm{f}^{2}+$

$0.14500 \times \mathrm{d}^{2}-0.04583 \times \mathrm{V} \times \mathrm{f}+$

$0.05000 \times \mathrm{V} \times \mathrm{d}-0.09750 \times \mathrm{f} \times \mathrm{d}$

Table 6 shows the ANOVA table for RSM model for cutting force when machining MMC with uncoated tool.

The regression model fitted for cutting force was obtained and is represented by Eq.3:

Cutting force $(\mathrm{Fz})=103.279-26.401 \times$

$\mathrm{V}+54.036 \times \mathrm{f}+41.987 \times \mathrm{d}+32.521$

$\times \mathrm{f}^{2}+7.653 \times \mathrm{d} 2-23.75 \times \mathrm{V}$

$\mathrm{f}+15.242 \times \mathrm{V} \times \mathrm{d}+9.045 \times \mathrm{f} \times \mathrm{d}$

The predicted results were discussed through the Table 7-9 with experimental validation. The error range obtained during that analysis was between 3.9 to $11 \%$ and it was considered as acceptable model.

\section{RESULTS}

The observed readings are ploted in the following graphical illustrations of Fig. 1-3.

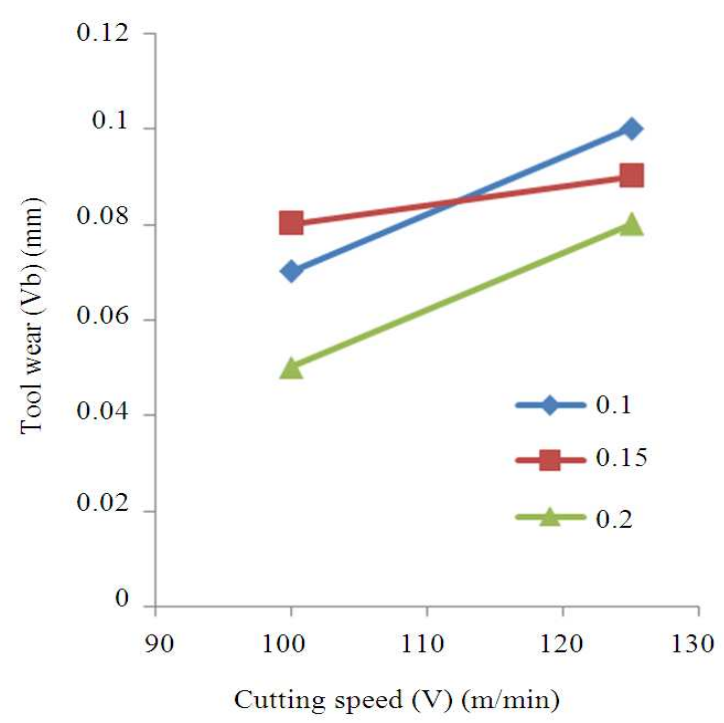

Fig. 1: Effect of cutting speed on Tool wear with varying feed rate 
Am. J. Applied Sci., 9 (4): 478-483, 2012

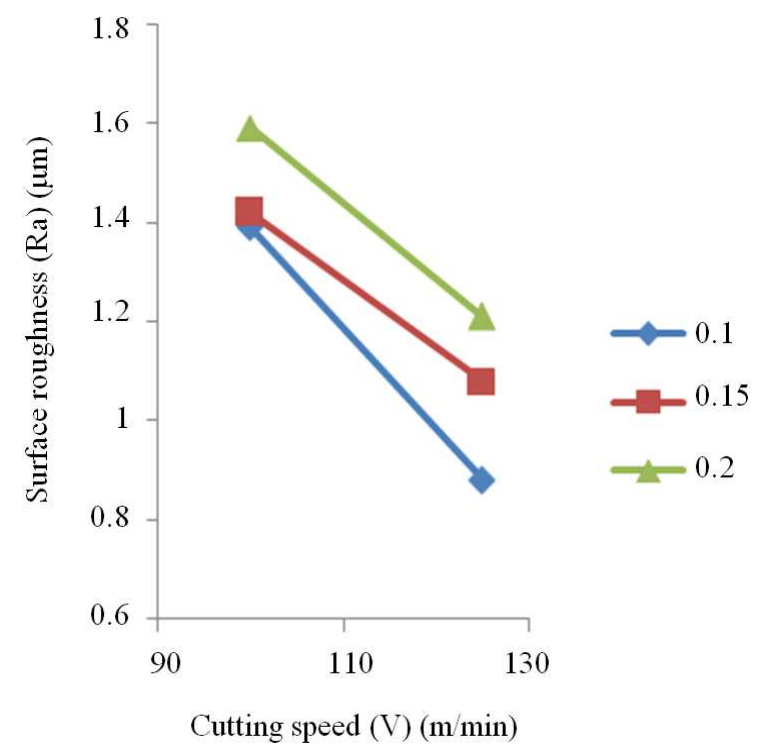

Fig. 2: Effect of cutting speed on surface roughness with varying feed rate

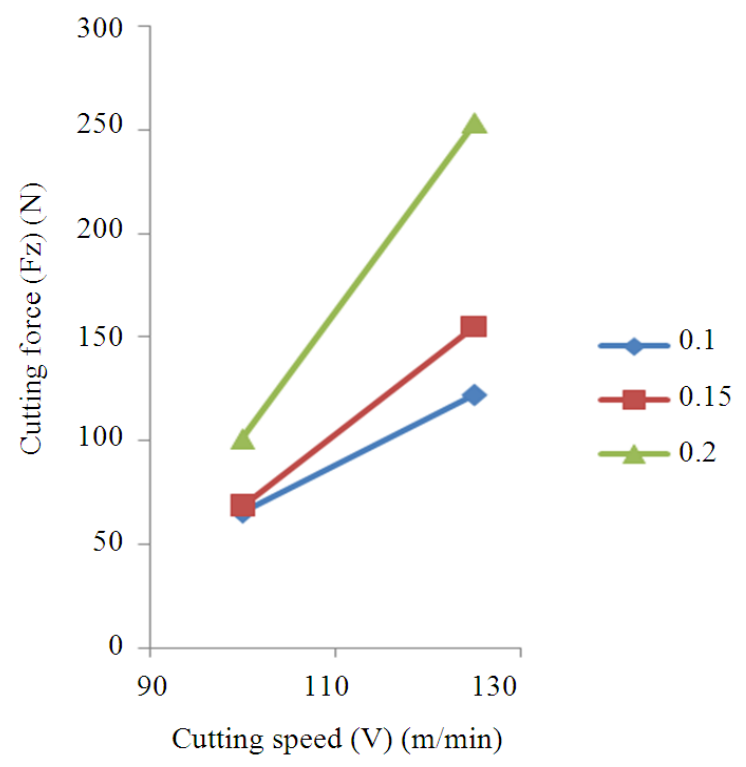

Fig. 3: Effect of Cutting speed on Cutting force with varying Feed rate

\section{DISCUSSION}

Effect of cutting parameters on tool wear: The effect of cutting speed on the tool wear is shown in Fig. 1. It shows that increase in tool wear increases the cutting speed. It is clear that the flank wear (Vbmax) increases with increase in cutting speed, at lower cutting speed tool wear is lesser extended (Seeman et al., 2010).
Effect of cutting parameters on surface roughness: The effect of Cutting speed on Surface roughness is shown in Fig. 2. It shows that, the surface roughness decreases with increase in the cutting speed. Surface roughness ( $\mathrm{Ra}$ ) decreases as the cutting speed (S) increases. At low cutting speed (s), the unstable larger BUE is formed and also the chips fracture readily producing the rough surface. As the cutting speed (s) increases, the BUE vanishes, chip fracture decreases and, hence, the roughness decreases (Palanikumar and Karthikeyan, 2007). A better surface finish was achieved at the lowest feed rate and highest cutting speed combination.

Effect of cutting parameters on cutting force: The variation of cutting force with cutting speed is shown in Fig. 3. It shows that increase in cutting speed increases the cutting force. When the feed is more the cutting force shows higher in nano particles when compared to micron MMC.

\section{CONCLUSION}

- RSM model have been developed for predicting tool life, surface roughness and cutting force

- The optimized cutting condition that gives lower surface finish and cutting force when machining micron MMCs have been identified: Cutting speed 'V' $100 \mathrm{~m} \mathrm{~min}^{-1}$, Feed 'f' $0.1 \mathrm{~mm} / \mathrm{rev}$ and Depth of cut 'a' $0.10 \mathrm{~mm}$

- The surface roughness improves with increase of the cutting speed whilst increasing feed adversely affects the surface roughness

- The tool wear increases with increase of the cutting speed, the feed and the depth of cut. Among the machining parameters cutting speed has the most dominant effect on tool wear

- The cutting force almost linearly varies with feed. At low cutting speed the cutting force is higher and the interactions of cutting speed with feed and depth of cut with feed dominantly affects the cutting forces

- The machining parameters for turning process are optimized using Taguchi's technique for minimizing the tool wear, surface roughness and cutting force

- The developed model has been validated experimentally and exhibit low values of error.

\section{REFERENCES}

Box, G.E.P. and K.B. Wilson, 1951. On the experimental attainment of optimum conditions. J. Royal Stat. Soc. Series B (Methodol.), 13: 1-45. 
Davim, J.P., 2002. Diamond tool performance in machining metal-matrix composites. J. Mater Process Technol., 128: 100-105. DOI: 10.1016/S0924-0136(02)00431-4

Davim, J.P., 2007. Application of merchant theory in machining particulate metal matrix composites. Mater. Des., 28: 2684-2687. DOI: 10.1016/j.matdes.2006.10.015

Hashim, J., L. Looney and M.S.J. Hashmi, 1999. Metal matrix composites: Production by the stir casting method. J. Mater. Process. Technol., 92-93: 1-7. DOI: 10.1016/S0924-0136(99)00118-1

Iqbal, A.K.M.S and A.A. Khan, 2010. Modeling and analysis of MRR, EWR and surface roughness in EDM milling through response surface methodology. Am. J. Eng. Applied Sci., 3: 611619. DOI: 10.3844/ajeassp.2010.611.619

Kilıckap, E., O. Cakır, M. Aksoy and A. Inan, 2005. Study of tool wear and surface roughness in machining of homogenised SiC-p reinforced aluminium metal matrix composite. J. Mater. Process. Technol., 164-165: 862-867. DOI: 10.1016/j.jmatprotec.2005.02.109

Mannaa, A. and B. Bhattacharya, 2003. A study on machinability of Al/SiC-MMC. J. Mater. Process. Technol., 140: 711-716. DOI: 10.1016/S09240136(03)00905-1
Palanikumar, K. and R. Karthikeyan, 2007. Assessment of factors influencing surface roughness on the machining of $\mathrm{Al} / \mathrm{Sic}$ particulate composites. Mater. Design, 28: 1584-1591. DOI: 10.1016/j.matdes.2006.02.010

Pramanik, A., L.C. Zhang and J.A. Arsecularatne, 2006. Prediction of cutting forces in machining of metal matrix composites. Int. J. Mach. Tools Manuf., 46: 1795-1803.

DOI: 10.1016/j.ijmachtools.2005.11.012

Sahin, Y., 2003. Preparation and some properties of SiC particle reinforced aluminium alloy composites. Mater. Design, 24: 671-679. DOI: 10.1016/S02613069(03)00156-0

Seeman, M., G. Ganesen, R. Karthikeyan and A. Velayudham, 2010. Study on tool wear and surface roughness in machining of particulate aluminum metal matrix composite-response surface methodology approach. Int. J. Adv. Manuf. Technol., 48: 613-624. DOI: 10.1007/s00170-0092297-z

Shaw, M.C., 2005. Metal Cutting Principles. 2nd Edn., Oxford University Press, Oxford, New York, ISBN: 0195142063, pp: 651. 